\title{
Assessing The Consistency of Continuous Time Coefficient Parameter Model Using SEM Approach in Irregular Time Data
}

\author{
Erica Fera Juwita ${ }^{1}$, Asep Saefuddin ${ }^{1,}$ Bagus Sartono ${ }^{1}$ \\ ${ }^{I}$ Department of Statistics, Bogor Agricultural University, Indonesia
}

\begin{abstract}
Limitations record on a variable which have continuous variable changes make the 'time' attached to the data is discrete. That underlies development of continuous time model. Compared to discrete time model, the continuous time model has advantages that can make prediction at different lag. In addition, it still can perform continuous time model parameter estimation, although the objects observations do not always have the same time interval (irregular time). Thus, the purpose of this study is to examine the consistency of continuous time model coefficient parameter with structural equation model (SEM) approach in irregular time data. The method used is the Exact Discrete Model (EDM) with SEM approach. EDM is a model that connects the parameter to value which is underlying parameter of the continuous time model with non-linear relationships. The result analysis of the research indicated that the coefficients of continuous time model parameter are still consistent until $20 \%$ of irregular time with $5 \%$ consistency limits.
\end{abstract}

Keywords: Irregular Time, Continuous Time Model, EDM, Consistency of Parameter Coefficient

\section{Introduction}

Observation and survey are common approach in science to collect the time series data, collected by conduct a set of fixed observation time in a period to a certain object. Autoregressive, Moving Average and ARIMA are some models which are used in time series to obtain the forecast values of the observed data. Variable values are not only determined by its value from the previous period, but also influenced by other variable's value in the same observation time, which is called cross-lagged. Some approach already developed to determine the model value i.e. Vector Autoregressive (VAR) [1] and Vector Error Correction Model (VECM) [2] for multivariable with single object. Panel model [3] is used for multivariable and multi objects. The models is called discrete time model, because the prediction is only used for different time interval which is the result of multiple observation time.

$\mathrm{Yu}$ (2011) argues many variables have continuously changed, but due to the lack of recording method which results to discrete time data [4]. Thus the discrete model cannot be used to predict continuously. From this condition, it is already developed a model called as continuous time model which allow the researcher to predict in different observation time continuously, although the observation is conducted in a discrete time method.

Philip (1959) is an econometrician who developed the first detail algorithm to estimate continuous time model in discrete which is used in macroeconomic [5]. But his algorithm produces inefficient asymptotic prediction. Bergstrom (1966) introduced Exact Discrete Model (EDM), a model that links the discrete time parameter to the basic value of continuous model parameter in a non-linear way and a simultaneous formula model is used to predict the EDM parameter [6]. Oud and Jansen (2000) show how SEM package as like Mx is used to predict a continuous time model parameter using direct method, directly applying the non-linear EDM relationship at the time of estimation [7]. A study conducted by Voelke et al. (2012), using a continuous-time model analysis with SEM approach to examine the relationship between Authoritarianism and Anomia [8]. In addition, the same was done by Toharudin et al. (2014) addressing the relationship between Individualism, Nationalism, Ethnocentrism and Authoritarianism in Flanders [9].

Besides used for prediction at various intervals (continuous), continuous time model also has other advantages compared to discrete time models. Continuous time model are still can be used for prediction, although the observation objects do not always have the same time interval (irregular). However, Voelke et al. (2012) stated that the irregularity should occur equally for each observation object if it involves more than one objects, or referred to as an irregular time data. In some previous studies, continuous time model with SEM approach often uses irregular time data; the researchers are interested in assessing the consistency of the continuous time model parameters for bivariate data. To that end, this study used the data on Literacy Rate (LR) and the Regional Budget in Education (RBE) as completes data as a benchmark to assess the consistency of continuous time parameters model in irregular time data. 


\section{Material and Methods}

\subsection{Data}

The data used in this study is a secondary data consists of the percentage of Literacy Rate (LR) and the percentage of Regional Budget by Educational Affairs (RBE) period 2008-2012 in education sector, each of which is obtained from www.bps.go.id and www.dpjk.kemenkeu.go.id. Based on budget data, it is known that the number of region in Indonesia in 2008 as many as 451 (not included in the provincial city of Jakarta), in 2009 as many as 477 region, in 2010 as many as 486 region, in 2011 as many as 491 region, and in 2012 as many as 487 region. Therefore, it needs to have a full observation values for both variables in the period of $2008-2012$, so that only 433 region are selected as the complete data.

\subsection{Methods}

Step-by-step analysis conducted in this study is as follows:

$\underline{\text { Step } 1}$

Conduct simulation data that will be used as the irregular time data, in a way of:

1. Eliminating some random observations from the complete data, so the data obtained within the observation have irregular intervals. The number of observations were removed classified into 5 types:

a. Eliminate $5 \%$ of the observations complete data (simulated data 1 ).

b. Eliminate $10 \%$ of the observations complete data (simulated data 2 ).

c. Eliminate $20 \%$ of the observations complete data (simulated data 3 ).

d. Eliminate $50 \%$ of the observations complete data (simulated data 4 ).

e. Eliminate $70 \%$ of the observations complete data (simulated data 5 ).

2. Repeat steps 1 (a), 1 (b), 1 (c), 1 (d), and 1 (e) 100 times with different randomization, with the aim to obtain 100 groups of data for each simulation.

3. In performing step 1, note that the observations which must be removed is a pair of observations at a certain period (LR and RBE observations variables omitted together in a certain period). Then in one observation does not eliminate all observations in 2008-2012.

$\underline{\text { Step } 2}$

1. EDM models based on equation (1):

$$
\mathbf{x}\left(t_{i}\right)=\mathbf{A}\left(\Delta t_{i}\right) \mathbf{x}\left(t_{i}-\Delta t_{i}\right)+\mathbf{b}+\mathbf{w}\left(\Delta t_{\mathbf{i}}\right)
$$

Perform estimation parameter EDM by using maximum likelihood method as shown in equation (2).

$$
F_{M L}=\log |\boldsymbol{\Sigma}|+\operatorname{tr}\left(\mathbf{S} \boldsymbol{\Sigma}^{-1}\right)-\log |\mathbf{S}|-(\mathbf{V}+1)
$$

This analysis using the M-PLUS 7 software.

2. Furthermore, the estimated parameters obtained in step 1, which consists of $\hat{\boldsymbol{\Phi}}\left[\mathbf{x}\left(\mathbf{t}_{\mathbf{0}}\right)\right], \hat{\boldsymbol{\mu}}_{\mathbf{x}\left(\mathbf{t}_{\mathbf{0}}\right)}, \hat{\mathbf{Q}}\left(\Delta \mathbf{t}_{\mathbf{i}}\right), \hat{\mathbf{b}}$, and $\hat{\mathbf{A}}$ (drift matrix) used as the initial value in estimate the parameters continuous time model.

3. Standardizing the A (matrix drift) obtained in step 2, by the formula;

$$
\mathbf{A}^{*}=\frac{\hat{\mathbf{A}}\left(\Delta t_{\mathbf{i}}\right)-\mathbf{I}}{\Delta t_{\mathbf{i}}}
$$

4. Estimation parameters for continuous time model with the same method in step 1, in accordance with the model in equation (4):

$$
\mathbf{x}\left(t_{i}\right)=\mathbf{e}^{\mathbf{A} \cdot \Delta t_{i}} \mathbf{x}\left(t_{i}-\Delta t_{i}\right)+\mathbf{A}^{-1}\left(\mathbf{e}^{\mathbf{A} \cdot \Delta t_{i}}-\mathbf{I}\right) \mathbf{b}+\mathbf{w}\left(\Delta t_{i}\right)
$$

With initial values obtained in step 2 consisting of $\hat{\boldsymbol{\Phi}}\left[\mathbf{x}\left(\mathbf{t}_{\mathbf{0}}\right)\right], \hat{\boldsymbol{\mu}}_{\mathbf{x}\left(\mathbf{t}_{\mathrm{t}}\right)}, \hat{\mathbf{Q}}\left(\Delta \mathbf{t}_{\mathbf{i}}\right), \hat{\mathbf{b}}$, and $\mathbf{A}^{*}$ obtained from step 3 is used to estimate the parameters of continuous time model, in order to obtain the estimated value corresponding to the elements of the matrix B and $\Psi$ the following;

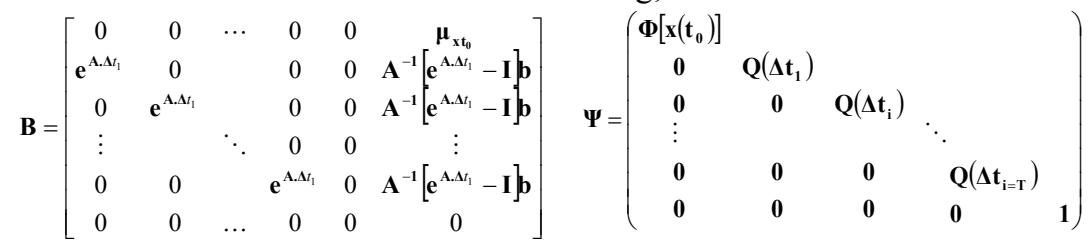

This analysis uses R 2.15. software (open Mx)

5. After acquiring the estimates value for the continuous time parameters models in step 4 , then calculates the estimated value of various parameters on the desired interval using the formula in equation (5).

$$
\mathbf{A}\left(\Delta t_{i}\right)=\mathbf{e}^{\mathbf{A} \cdot \Delta t_{i}}=\mathbf{I}+\mathbf{A} \cdot \Delta t_{\mathrm{i}}+\frac{1}{2 !} \mathbf{A}^{2} \cdot \Delta t_{\mathbf{i}}^{2}+\frac{1}{3 !} \mathbf{A}^{3} \cdot \Delta t_{\mathrm{i}}{ }^{3}+\ldots
$$


6. Calculates the parameter estimation of continuous time model in steps 4 and 5 for all the simulation data using the initial value in step 2 and 3.

$\underline{\text { Step } 3}$

Compare the value of coefficient A (drift matrix consisting of autoregressive coefficients on the main diagonal and cross-lagged coefficients on the other diagonal) obtained from the estimated continuous time parameters model on simulated data 1, 2, 3, 4, and 5 (data irregular time ) with complete data. The coefficient estimation for the continuous time parameters model is consistent when the coefficient estimation value for irregular time data parameters is between the lower control limit (LCL) and the upper control limit (UCL). Coefficients estimated complete data parameter is limited to $5 \%$.

\subsection{Continuous Time Parameter Model Estimation}

\section{Result and Discussion}

In a continuous time model, an initial value is acquired from the coefficient estimation for the EDM parameters on $\Delta \mathrm{t}_{\mathrm{i}}=1$, which is then used to estimate parameters for different models of continuous time $\Delta \mathrm{t}_{\mathrm{i}}$. The initial value of EDM parameters or results to be different when $\Delta \mathrm{t}_{\mathrm{i}}=1$ can be seen in Table 1.

Tabel 1 Parameter Estimates of EDM for $\Delta t_{i}=1$

\begin{tabular}{|c|c|c|c|}
\hline Parameter & EDM Coefficient & SE & P-value \\
\hline \multicolumn{4}{|l|}{ Autoregressive } \\
\hline $\mathrm{A}_{\mathrm{amam}}$ & $0.845\left(-0.155^{\mathrm{a}}\right)$ & 0.014 & $0.000^{\mathrm{b}}$ \\
\hline $\mathrm{A}_{\text {apap }}$ & $0.974\left(-0.026^{a}\right)$ & 0.004 & $0.000^{\mathrm{b}}$ \\
\hline \multicolumn{4}{|l|}{ Cross-Lagged } \\
\hline $\mathrm{A}_{\text {amap }}$ & $0.018\left(0.018^{\mathrm{a}}\right)$ & 0.015 & 0.193 \\
\hline $\mathrm{A}_{\text {apam }}$ & $0.002\left(0.002^{\mathrm{a}}\right)$ & 0.003 & 0.633 \\
\hline \multicolumn{4}{|l|}{ Laten Intercept } \\
\hline$b_{a m}$ & 0.489 & 0.149 & $0.001^{\mathrm{b}}$ \\
\hline$b_{a p}$ & 0.261 & 0.035 & $0.000^{\mathrm{b}}$ \\
\hline \multicolumn{4}{|l|}{ Residual } \\
\hline $\operatorname{var}\left(\mathrm{w}_{\mathrm{am}}\right)$ & 0.450 & 0.016 & $0.000^{\mathrm{b}}$ \\
\hline $\operatorname{var}\left(w_{a p}\right)$ & 0.026 & 0.001 & $0.000^{\mathrm{b}}$ \\
\hline $\operatorname{covar}\left(\mathrm{W}_{\text {apam }}\right)$ & -0.001 & 0.003 & 0.720 \\
\hline \multicolumn{4}{|c|}{ Initial Measurement } \\
\hline $\mathrm{M}\left(\mathrm{am}_{\mathrm{t} 0}\right)$ & 2.783 & 0.047 & $0.000^{\mathrm{b}}$ \\
\hline $\mathrm{M}\left(\mathrm{ap}_{\mathrm{t} 0}\right)$ & 9.287 & 0.051 & $0.000^{\mathrm{b}}$ \\
\hline $\operatorname{var}\left(\mathrm{am}_{\mathrm{t} 0}\right)$ & 0.996 & 0.067 & $0.000^{\mathrm{b}}$ \\
\hline $\operatorname{var}\left(a p_{t 0}\right)$ & 1.148 & 0.077 & $0.000^{\mathrm{b}}$ \\
\hline $\operatorname{cov}\left(\mathrm{am}_{\mathrm{t} 0}, \mathrm{ap}_{\mathrm{t} 0}\right)$ & 0.064 & 0.051 & 0.203 \\
\hline
\end{tabular}

a. standardize value of drift matrix (A*); b. significant of $\alpha=5 \%$

From Table 1, it can be seen that the autoregressive parameter coefficient of LR and RBE percentage are significant at the $5 \%$, with a coefficient value of the estimated parameter for 0.845 and 0.974 . This means that there is a significant relationship between the variables of the current period LR (LRt) with LR in the previous period (LRt-1). So does the RBE variable percentage in this period (RBEt) and percentage of the RBE in the previous period (RBEt-1).

Moreover, noted that the cross-lagged parameters coefficient of LR and RBE percentage are not significant at the $5 \%$ significance level, with a coefficient values for 0.018 and 0.002 . This means that there is no relationship between the LR percentages in the current period (LRt) with the RBE in the previous period (RBEt-1). Vice versa, there is no relationship between the RBE percentages this period (RBEt) with the LR in the previous period (LRt-1).

After obtaining results of estimated EDM, drift matrix $\left(\mathrm{A}^{*}\right)$ which consists of autoregressive and crosslagged should be standardized first. From Table 1, it can be seen the standardized values of the drift matrix for autoregressive value -0.155 and -0.026 , whereas the cross-lagged values of 0.018 and 0.002 . Then the initial value used to estimate continuous time model is the standardized drift matrix value (autoregressive and crosslagged), latent intercept, residual, and initial measurement obtained from the EDM estimation.

Table 2 Parameter Estimates of Continuous Time Model for Unequal Intervals

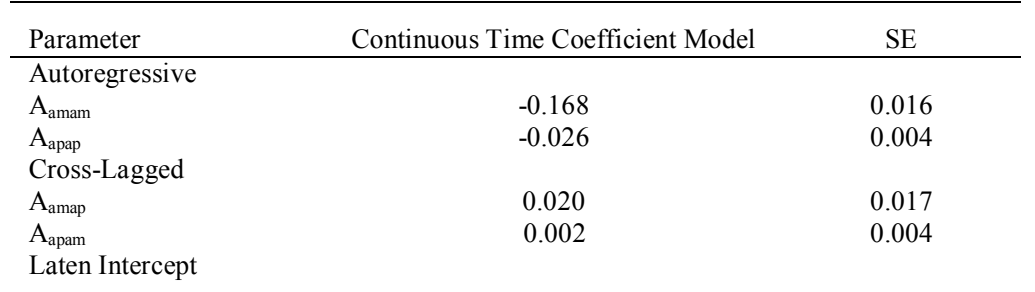




\begin{tabular}{lcc}
$\mathrm{b}_{\mathrm{am}}$ & 0.528 & 0.161 \\
$\mathrm{~b}_{\mathrm{ap}}$ & 0.264 & 0.036 \\
Residual & & \\
$\operatorname{var}\left(\mathrm{w}_{\mathrm{am}}\right)$ & 0.529 & 0.020 \\
$\operatorname{var}\left(\mathrm{w}_{\mathrm{ap}}\right)$ & 0.026 & 0.001 \\
covar $\left(\mathrm{w}_{\mathrm{apam}}\right)$ & -0.002 & 0.003 \\
$\mathrm{Initial} \mathrm{Measurement}$ & & \\
$\mathrm{M}\left(\mathrm{am}_{\mathrm{t} 0}\right)$ & 2.783 & 0.047 \\
$\mathrm{M}\left(\mathrm{ap}_{\mathrm{t} 0}\right)$ & 9.286 & 0.051 \\
$\operatorname{var}\left(\mathrm{am}_{\mathrm{t} 0}\right)$ & 0.996 & 0.067 \\
$\operatorname{var}\left(\mathrm{ap}_{\mathrm{t} 0}\right)$ & 1.148 & 0.077 \\
$\operatorname{cov}\left(\mathrm{am}_{\mathrm{t} 0}, \mathrm{ap}_{\mathrm{t} 0}\right)$ & 0.064 & 0.051 \\
\hline
\end{tabular}

Parameter estimation results in Table 2 shows that the value of the autoregressive and cross-lagged obtained is almost close to the initial value. Autoregressive variable value of LR and RBE percentage obtained at -0.168 and -0.026 , with SE values respectively 0.016 and 0.004 . Then the cross-lagged values are 0.020 and 0.002 , with SE values 0.017 and 0.004 .

Table 3 Estimation Result of Continuous Time Model for Unequal Intervals

\begin{tabular}{lccc}
\hline \multicolumn{1}{c}{ Parameter } & $\Delta \mathrm{t}_{\mathrm{i}}=1^{\mathrm{a}}$ & $\Delta \mathrm{t}_{\mathrm{i}}=2^{\mathrm{b}}$ & $\Delta \mathrm{t}_{\mathrm{i}}=0.5^{\mathrm{c}}$ \\
\hline Autoregressive & & & \\
$\mathrm{A}_{\text {amam }}$ & 0.845 & 0.715 & 0.919 \\
$\mathrm{~A}_{\text {apap }}$ & 0.974 & 0.949 & 0.987 \\
Cross-Lagged & & & \\
$\mathrm{A}_{\text {amap }}$ & 0.002 & 0.003 & 0.001 \\
$\mathrm{~A}_{\text {apam }}$ & 0.020 & 0.041 & 0.010 \\
\hline
\end{tabular}

a. Estimation for lag 1th (1 years)

b. Estimation for lag 2 th ( 2 years)

c. Estimation for lag 0.5 th (6 month)

Table 3 shows the results of different parameter estimation stage of annual, biennial, and six monthly. Seen from the parameter value at various $\Delta \mathrm{t}_{\mathrm{i}}$, autoregressive parameter coefficient is decreases when $\Delta \mathrm{t}_{\mathrm{i}}$ value for prediction is larger than $\Delta \mathrm{t}_{\mathrm{i}}$ value at discrete periods. In this case, $\Delta \mathrm{t}_{\mathrm{i}}$ value $=1$ (lag 1 th) are 0.845 and 0.974 , then the coefficient value decreases when the prediction is done at $\Delta \mathrm{t}_{\mathrm{i}}=2$ (lag 2th) which is equal to 0.715 and 0.949 . In contrast, the autoregressive coefficient value increases when $\Delta \mathrm{t}_{\mathrm{i}}$ value for prediction is smaller than $\Delta \mathrm{t}_{\mathrm{i}}$ value at discrete periods, $\Delta \mathrm{t}_{\mathrm{i}}=0.5$ (lag 0.5 th) of 0.919 and 0.987 .

But, the cross-lagged coefficient parameters value to be otherwise, it increases when $\Delta \mathrm{t}_{\mathrm{i}}$ value for the prediction is larger than $\Delta \mathrm{t}_{\mathrm{i}}$ value at discrete periods, and decreases when $\Delta \mathrm{t}_{\mathrm{i}}$ for prediction is smaller than $\Delta \mathrm{t}_{\mathrm{i}}$ value at discrete periods. It can be seen from the cross-lagged coefficients obtained at $\Delta \mathrm{t}_{\mathrm{i}}=1$ (are 0.002 and 0.022 , then increased at $\Delta \mathrm{t}_{\mathrm{i}}=2$ of 0.003 and 0.041 , and decreased in $\Delta \mathrm{t}_{\mathrm{i}}=0.5$ to 0.001 and 0.010 .

\subsection{Consistency Result of Continuous Time Parameter Modelling in Irregular Time Data}

Next step is conduct consistency test to coefficient estimation of the continuous time parameters model to irregular time data $5 \%, 10 \%, 20 \%, 50 \%$, and $70 \%$. The test was done by comparing the coefficient estimation value of continuous time parameters model obtained at irregular time data versus the coefficient estimation parameters obtained in the complete data. The upper control limit (UCL) and the lower control limit (LCL) of the coefficient estimation value for the continuous time parameters model using complete data, obtained from $5 \%$ consistency value determined at the beginning of the study. Irregular time data is consistent if the coefficient estimation value for the parameters is between UCL and LCL with 5\% consistency limit.

In this research, there are 100 coefficients parameter in each element of drift matrix ( $\mathrm{A}^{*}$ ) in each irregular time data $5 \%, 10 \%, 20 \%, 50 \%$, and $70 \%$, which is compared with the coefficient A (matrix drift) estimated results continuous time parameters on the complete data. Consistency coefficient test result of $\mathrm{A}^{*}$ (matrix drift) from estimated parameter for continuous time model in irregular time data $\Delta \mathrm{t}_{\mathrm{i}}=1$ can be seen in Table 4.

From Table 4 known that autoregressive parameters estimated value of LR percentage $\left(\mathrm{A}_{\text {amam }}\right)$ at $\Delta \mathrm{t}_{\mathrm{i}}=$ 1 for 0.845 , with a consistency limit of $5 \%$ obtained LCL values obtained for 0.819 and 0.872 for UCL. So it can be said $100 \%\left(\mathrm{~A}_{\text {amam }}\right)$ has been consistent with irregular time data $5 \%$ and $10 \%$. Then $96 \%$ coefficient to be consistent in the irregular time data of $20 \%$, and $16 \%$ coefficient consistent with irregular time data of $50 \%$ and $70 \%$. This means the percentage of coefficient autoregressive LR $\left(\mathrm{A}_{\text {amam }}\right)$ variable for $\Delta \mathrm{t}_{\mathrm{i}}=1$ can be said to be consistent up to $20 \%$ of irregular time data. 
Table 4 Consistency Result of Continuous Time Parameter Model in Irregular Time Data for $\Delta \mathrm{t}_{\mathrm{i}}=1$

\begin{tabular}{|c|c|c|c|c|c|c|c|c|c|}
\hline \multirow{2}{*}{ Parameter } & \multirow{2}{*}{$\begin{array}{c}\text { Complete } \\
\text { Data }\end{array}$} & \multirow{2}{*}{$\begin{array}{l}\text { Consistency } \\
\text { Limit }\end{array}$} & \multirow{2}{*}{ LCL } & \multirow{2}{*}{ UCL } & \multicolumn{5}{|c|}{ Irregular Time Data $(\%)^{\mathrm{a}}$} \\
\hline & & & & & $5 \%$ & $10 \%$ & $20 \%$ & $50 \%$ & $70 \%$ \\
\hline \multirow{3}{*}{$\mathrm{A}_{\mathrm{amam}}$} & \multirow{3}{*}{0.845} & $1 \%$ & 0.811 & 0.881 & 100 & 100 & 100 & 31 & 29 \\
\hline & & $5 \%$ & 0.819 & 0.872 & 100 & 100 & 96 & 16 & 16 \\
\hline & & $10 \%$ & 0.823 & 0.868 & 100 & 100 & 87 & 10 & 12 \\
\hline \multirow{3}{*}{$\mathrm{A}_{\text {apap }}$} & \multirow{3}{*}{0.974} & $1 \%$ & 0.964 & 0.984 & 100 & 100 & 100 & 95 & 58 \\
\hline & & $5 \%$ & 0.967 & 0.982 & 100 & 100 & 100 & 90 & 47 \\
\hline & & $10 \%$ & 0.968 & 0.981 & 100 & 100 & 100 & 80 & 40 \\
\hline \multirow{3}{*}{$\mathrm{A}_{\text {amap }}$} & \multirow{3}{*}{0.020} & $1 \%$ & -0.021 & 0.068 & 100 & 100 & 100 & 100 & 93 \\
\hline & & $5 \%$ & -0.011 & 0.057 & 100 & 100 & 100 & 100 & 81 \\
\hline & & $10 \%$ & -0.006 & 0.051 & 100 & 100 & 100 & 100 & 74 \\
\hline \multirow{3}{*}{$\mathrm{A}_{\text {apam }}$} & \multirow{3}{*}{0.002} & $1 \%$ & -0.008 & 0.012 & 100 & 100 & 100 & 99 & 86 \\
\hline & & $5 \%$ & -0.006 & 0.010 & 100 & 100 & 100 & 98 & 77 \\
\hline & & $10 \%$ & -0.005 & 0.009 & 100 & 100 & 100 & 93 & 67 \\
\hline
\end{tabular}

a. The percentage of drift matrix $\left(\mathrm{A}^{*}\right)$ parameter coefficient in line with the irregular time data

Autoregressive parameters estimated value of RBE percentage $\left(\mathrm{A}_{\text {apap }}\right)$ at $\Delta \mathrm{t}_{\mathrm{i}}=1$ for 0974 , with a limit of 5\% consistency LCL values obtained for 0.967 and 0.981 for UCL. It's mean that $100 \%\left(\mathrm{~A}_{\text {apap }}\right)$ consistent with irregular time data of 5\%,10\%, and 20\%. Then 95\% $\left(\mathrm{A}_{\text {apap }}\right)$ are consistent with irregular time data of 50\% and $58 \%\left(\mathrm{~A}_{\text {apap }}\right)$ consistent with irregular time data of $70 \%$. This means $\left(\mathrm{A}_{\text {apap }}\right)$ for $\Delta \mathrm{t}_{\mathrm{i}}=1$ is said to be consistent to the $50 \%$ of irregular time data.

Then the cross-lagged parameters, the relationship between the LR percentage at current period with the RBE percentage in the previous periods $\left(\mathrm{A}_{\text {amap }}\right)$ at $\Delta \mathrm{t}_{\mathrm{i}}=1$ obtained parameter values estimation of 0.020 . With 5\% consistency limit values obtained LCL and UCL for $0.057-0.011$. So it is known that $100 \%$ crosslagged coefficients $\left(\mathrm{A}_{\text {amap }}\right)$ can be said consistent with the irregular time data 5\%, 10\%, 20\%, and 50\%. As much as $81 \%$ of cross-lagged coefficients $\left(\mathrm{A}_{\text {amap }}\right)$ are consistent at $70 \%$ of irregular time data. This means that the cross-lagged coefficients $\left(\mathrm{A}_{\text {amap }}\right)$ at $\Delta \mathrm{t}_{\mathrm{i}}=1$ is said to be consistent to the $70 \%$ of irregular time data.

In addition, the relationship between the percentage of the RBE in this period with the percentage of LR in the previous period $\left(\mathrm{A}_{\text {apam }}\right)$ at $\Delta \mathrm{t}_{\mathrm{i}}=1$ estimated for 0.002 , with $5 \%$ consistency limit values obtained by the LCL and UCL for $0.010-0.006$. For that, it can be seen that $100 \%$ cross-lagged coefficients $\left(\mathrm{A}_{\text {apam }}\right)$ consistently on irregular time of data $5 \%, 10 \%$, and $20 \%$. Then $93 \%$ of cross-lagged coefficients $\left(\mathrm{A}_{\text {apam }}\right)$ are consistent with irregular time data $50 \%$, and as much as $77 \%$ cross-lagged coefficients $\left(\mathrm{A}_{\text {apam }}\right)$ consistent with irregular data time $70 \%$. This means that the cross-lagged coefficients $\left(\mathrm{A}_{\text {apam }}\right)$ for $\Delta \mathrm{t}_{\mathrm{i}}=1$ can be said to be consistent up to $70 \%$ of irregular time data.

The coefficient consistency test results on estimated continuous time parameters model for the data in irregular time $\Delta \mathrm{t}_{\mathrm{i}}=1, \Delta \mathrm{t}_{\mathrm{i}}=2$ and $\Delta \mathrm{t}_{\mathrm{i}}=0.5$ can be found in the appendix. For autoregressive parameters LR $\left(\mathrm{A}_{\text {amam }}\right)$ on $\Delta \mathrm{t}_{\mathrm{i}}=2$ obtained coefficient values of parameter estimates for the full data 0.714 , with a limit of $5 \%$ consistency LCL and UCL obtained for 0.671 and 0.761 . Education budget for autoregressive parameters $\left(\mathrm{A}_{\text {apap }}\right)$ coefficient values obtained parameter estimates for the full data for 0.949 , with a limit of $5 \%$ consistency LCL and UCL obtained for 0.935 and 0.964. In the cross-lagged parameters, the percentage of LR current relationship with the percentage of the $\mathrm{RBE}$ of the previous period $\left(\mathrm{A}_{\mathrm{amap}}\right)$ coefficient values obtained parameter estimates for the full data for 0.041, with a limit of 5\% consistency obtained LCL and UCL -0.022 and 0.105. For cross-lagged parameters, the relationship between current RBE percentages with previous period LR percentage $\left(\mathrm{A}_{\text {apam }}\right)$, obtained coefficient values parameter estimates for the full data 0.003 , with a limit of $5 \%$ consistency obtained LCL and UCL - 0.012 and 0.020 .

The estimate coefficient parameter consistency test of irregular time data at $\Delta \mathrm{t}_{\mathrm{i}}=0.5 \mathrm{known}$ that the autoregressive LR parameters $\left(\mathrm{A}_{\mathrm{amam}}\right)$ has parameter estimates coefficient value from the full data for 0.919 , with a limit of 5\% consistency earned LCL and UCL 0.905 and 0.934 . Autoregressive parameters for RBE $\left(\mathrm{A}_{\text {apap }}\right)$ has parameter estimates coefficient values for the full data 0.987 , with a limit of $5 \%$ consistency earned LCL and UCL 0.983 and 0.991 . Then for cross-lagged parameters, the percentage of LR in current relationship with the percentage of the RBE of the previous period $\left(\mathrm{A}_{\mathrm{amap}}\right)$ obtained coefficient values parameter estimates for the full data for 0.010, with consistency limit of 5\% obtained LCL and UCL respectively -0.006 and 0.028 . The cross-lagged parameters, the relationship between to the current RBE and LR percentage to the previous $\left(\mathrm{A}_{\text {apam }}\right)$ percentage obtained coefficient values parameter estimates for the full data 0.001 , with a limit of $5 \%$ consistency earned LCL and UCL respectively -0.003 and 0.005 .

Although it is known that the parameter coefficient of continuous time model at $\Delta \mathrm{t}_{\mathrm{i}}=2$ and $\Delta \mathrm{t}_{\mathrm{i}}=0.5$ are different with $\Delta \mathrm{t}_{\mathrm{i}}=1$. Yet, the number of coefficients parameters that consistent to the irregular time data $5 \%$, $10 \%, 20 \%, 50 \%$, and $70 \%$ as same as with $\Delta \mathrm{t}_{\mathrm{i}}=1$. Therefore, in regard to the overall parameters of continuous time model it can be concluded that the consistency limit of 5\% coefficient estimation for continuous time parameters model various $\Delta \mathrm{t}_{\mathrm{i}}$ only consistent up to $20 \%$ of irregular time data. 


\section{Conclusion}

Parameter estimation is performed at interval $\Delta \mathrm{t}_{\mathrm{i}}=1, \Delta \mathrm{t}_{\mathrm{i}}=2$, and $\Delta \mathrm{t}_{\mathrm{i}}=0.5$. From the results of parameter estimation on different $\Delta \mathrm{t}_{\mathrm{i}}$, it is known that on the large time interval $\left(\Delta \mathrm{t}_{\mathrm{i}}=2\right)$ obtained value of the parameter estimation of continuous time model is smaller than the interval at discrete periods. In contrast to the smaller time interval $\left(\Delta \mathrm{t}_{\mathrm{i}}=0.5\right)$ obtained larger parameter estimation values of continuous time model than the interval on the discrete periods. Then, after testing the consistency of coefficient estimation for continuous time parameters model to the data for various irregular time $\Delta \mathrm{t}_{\mathrm{i}}$, it can be seen that consistency limit of $5 \%$, coefficient estimation for continuous time parameters model are consistent only up to $20 \%$ of irregular time data for bivariate data.

\section{References}

[1] Sims, C.A., Macroeconomics and Reality, Econometrics, Vol.48,1-47, 1980.

[2] Engle, R.F., Granger, C.W.J., Co-integration and Error Correction Representation, Estimation, and Testing, Econometric, 55.251276, 1987.

[3] Baltagi, B.H., Econometric Analysis of Panel Data. 3th Edition (England (GB), John Wiley, 2005).

[4] Yu, J., Econometric Analysis of Continuous Time Models: A Survey of Peter Phillip's Work and Some New Results. Econometric Theory, 2001.

[5] Phillips, A.W., The Estimation of Parameters in Systems of Stochastic Differential Equations. Biometric, 1959, 46:67-76.

[6] Bergstrom, A.R., Non-recursive Models as Discrete Approximations to Systems of Stochastic Differential Equations. Econometric, 1966, 34: 173-182.

[7] Oud, J.H.L. and Jansen, R.A.R.G., Continuous Time State Space Modeling of Panel Data by Means of SEM. Psychometrics, 2000, 65:199-215.

[8] Voelkle, M.C., Oud, J.H.L.,Davidov, E., and Schmidt, P., An SEM Approach to Continuous Time Modeling of Panel Data: Relating Authoritarianism and Anomia, Psychological Methods, 10.1037/a0027543, 2012.

[9] Toharudin, T., Oud, J.H.L., Folmer, H., and Yenni, A., The Relationships Between Individualism, Nationalism, Ethnocentrism, and Authoritarianism in Flanders: A Continuous Time-Structural Equation Modeling Approach, Multivariate Behavioral Research, 2014, 49:41-53.

APPENDix A

Consistency Result of Continuous Time Parameter Model in Irregular Time Data for $\Delta t_{i}=2$

\begin{tabular}{|c|c|c|c|c|c|c|c|c|c|}
\hline \multirow{2}{*}{ Parameter } & \multirow{2}{*}{$\begin{array}{c}\text { Complete } \\
\text { Data }\end{array}$} & \multirow{2}{*}{$\begin{array}{c}\text { Consistency } \\
\text { Limit }\end{array}$} & \multirow{2}{*}{ LCL } & \multirow{2}{*}{ UCL } & \multicolumn{5}{|c|}{ Irregular Time Data $(\%)^{\mathrm{a}}$} \\
\hline & & & & & $5 \%$ & $10 \%$ & $20 \%$ & $50 \%$ & $70 \%$ \\
\hline \multirow{3}{*}{$\mathrm{A}_{\mathrm{amam}}$} & \multirow{3}{*}{0.714} & $1 \%$ & 0.658 & 0.776 & 100 & 100 & 100 & 31 & 29 \\
\hline & & $5 \%$ & 0.671 & 0.761 & 100 & 100 & 96 & 16 & 16 \\
\hline & & $10 \%$ & 0.678 & 0.753 & 100 & 100 & 87 & 10 & 12 \\
\hline \multirow{3}{*}{$\mathrm{A}_{\text {apap }}$} & \multirow{3}{*}{0.949} & $1 \%$ & 0.930 & 0.969 & 100 & 100 & 100 & 95 & 58 \\
\hline & & $5 \%$ & 0.935 & 0.964 & 100 & 100 & 100 & 90 & 47 \\
\hline & & $10 \%$ & 0.937 & 0.962 & 100 & 100 & 100 & 80 & 40 \\
\hline \multirow{3}{*}{$\mathrm{A}_{\text {amap }}$} & \multirow{3}{*}{0.045} & $5 \%$ & -0.012 & 0.020 & 100 & 100 & 100 & 98 & 77 \\
\hline & & $10 \%$ & -0.009 & 0.017 & 100 & 100 & 100 & 93 & 67 \\
\hline & & $1 \%$ & -0.042 & 0.140 & 100 & 100 & 100 & 100 & 93 \\
\hline \multirow{3}{*}{$\mathrm{A}_{\text {apam }}$} & \multirow{3}{*}{0.003} & $1 \%$ & -0.016 & 0.025 & 100 & 100 & 100 & 99 & 86 \\
\hline & & $5 \%$ & -0.012 & 0.020 & 100 & 100 & 100 & 98 & 77 \\
\hline & & $10 \%$ & -0.009 & 0.017 & 100 & 100 & 100 & 93 & 67 \\
\hline
\end{tabular}

a. The percentage of drift matrix $\left(\mathrm{A}^{*}\right)$ parameter coefficient in line with the irregular time data

APpendix B

Consistency Result of Continuous Time Parameter Model in Irregular Time Data for $\Delta \mathrm{t}_{\mathrm{i}}=0.5$

\begin{tabular}{|c|c|c|c|c|c|c|c|c|c|}
\hline \multirow{2}{*}{ Parameter } & \multirow{2}{*}{$\begin{array}{l}\text { Complete } \\
\text { Data }\end{array}$} & \multirow{2}{*}{$\begin{array}{l}\text { Consistency } \\
\text { Limit }\end{array}$} & \multirow{2}{*}{ LCL } & \multirow{2}{*}{ UCL } & \multicolumn{5}{|c|}{ Irregular Time Data $(\%)^{\mathrm{a}}$} \\
\hline & & & & & $5 \%$ & $10 \%$ & $20 \%$ & $50 \%$ & $70 \%$ \\
\hline \multirow{3}{*}{$\mathrm{A}_{\mathrm{amam}}$} & \multirow{3}{*}{0.919} & $1 \%$ & 0.901 & 0.939 & 100 & 100 & 100 & 31 & 29 \\
\hline & & $5 \%$ & 0.905 & 0.934 & 100 & 100 & 96 & 16 & 16 \\
\hline & & $10 \%$ & 0.907 & 0.932 & 100 & 100 & 87 & 10 & 12 \\
\hline \multirow{3}{*}{$\mathrm{A}_{\text {apap }}$} & \multirow{3}{*}{0.987} & $1 \%$ & 0.982 & 0.992 & 100 & 100 & 100 & 95 & 58 \\
\hline & & $5 \%$ & 0.983 & 0.991 & 100 & 100 & 100 & 90 & 47 \\
\hline & & $10 \%$ & 0.984 & 0.990 & 100 & 100 & 100 & 80 & 40 \\
\hline \multirow{3}{*}{$\mathrm{A}_{\text {amap }}$} & \multirow{3}{*}{0.011} & $1 \%$ & -0.011 & 0.033 & 100 & 100 & 100 & 100 & 93 \\
\hline & & $5 \%$ & -0.006 & 0.028 & 100 & 100 & 100 & 100 & 81 \\
\hline & & $10 \%$ & -0.003 & 0.025 & 100 & 100 & 100 & 100 & 74 \\
\hline \multirow{3}{*}{$\mathrm{A}_{\mathrm{apam}}$} & \multirow{3}{*}{0.001} & $1 \%$ & -0.004 & 0.006 & 100 & 100 & 100 & 99 & 86 \\
\hline & & $5 \%$ & -0.003 & 0.005 & 100 & 100 & 100 & 98 & 77 \\
\hline & & $10 \%$ & -0.002 & 0.004 & 100 & 100 & 100 & 93 & 67 \\
\hline
\end{tabular}

a. The percentage of drift matrix $\left(\mathrm{A}^{*}\right)$ parameter coefficient in line with the irregular time data 